Article

\title{
Wave-Induced Oscillatory Flow Over a Sloping Rippled Bed
}

\author{
Carla Faraci ${ }^{1, *,+} \oplus$, Pietro Scandura ${ }^{2,+}$, Carmelo Petrotta ${ }^{1,+}$ and Enrico Foti ${ }^{2}$ \\ 1 Department of Engineering, University of Messina, 98166 Messina ME, Italy \\ 2 Department of Civil Engineering and Architecture, University of Catania, 95124 Catania CT, Italy \\ * Correspondence: carla.faraci@unime.it; Tel.: +39-090-676-5165 \\ + These authors contributed equally to this work.
}

Received: 24 June 2019; Accepted: 31 July 2019; Published: 5 August 2019

\begin{abstract}
In this paper, the findings of an experimental analysis aimed at investigating the flow generated by waves propagating over a fixed rippled bed within a wave flume are reported. The bottom of the wave flume was constituted by horizontal part followed by a 1:10 sloping beach. Bedforms were generated in a previous campaign performed with loose sand, and then hardened by means of thin layers of concrete. The flow was acquired through a Vectrino Profiler along two different ripples, one located in the horizontal part of the bed and the second over the sloping beach. It was observed that, on the horizontal bed, near the bottom, ripple lee side triggered the appearance of an onshore directed steady streaming, whereas ripple stoss side gave rise to an offshore directed steady streaming. On the sloping bed, a strong return current appears at all positions, interacting with the rippled bottom. The turbulence is non-negligible within the investigated water depth, particularly when velocities were onshore directed, due to flow asymmetry. Turbulence caused a considerable flow stirring which, above a non-cohesive bed, could lift the sediment up in the water column and give rise to a strong sediment transport.
\end{abstract}

Keywords: hydrodynamics; bedforms; velocity profiles; mean flow; statistics; acceleration skewness

\section{Introduction}

In coastal regions, waves propagating over a slope may become skewed, with sharp crests and flat troughs, and asymmetric, with steep fronts and gentle rear faces. Because of these wave characteristics, the time dependent velocity in the boundary layer becomes both skewed and asymmetric. Skewness consists in a difference between the two peaks of the velocity during the wave cycle. Asymmetry consists in a difference between the time derivative of the velocity during the two half cycle, thus it is referred as acceleration skewness [1].

Skewed and asymmetric waves strongly impact on the near bed hydrodynamics, generating asymmetry in bed shear stress and, in turn, in sediment flux in the two flow half-cycles, thus playing a crucial role in the wave-driven net sediment transport. Effects of velocity skewness on boundary layer flow and sediment transport have been studied, among others, by Ribberink and Al-Salem [2], who observed that the net sediment transport during the cycle is onshore directed while the average velocity is offshore directed. O'Donoghue and Wright [3] found that velocity skewness increases the onshore sediment transport but it generates also an offshore directed transport of fine sediments. A detailed experimental study on the hydrodynamics of acceleration-skewed oscillatory boundary layers on a rough wall was carried out by Van der A et al. [4]. They showed that the acceleration skewness leads to an asymmetry of the wall shear stress in the two half-cycles and to the appearance of a steady streaming opposite to the largest acceleration. Such mean velocity may also impact on the transport of fine sediments, which can be easily brought far away from the bottom [5]. 
Scandura et al. [6] studied acceleration skewed flows by means of a direct numerical simulation of the Navier-Stokes equations confirming the existence of an asymmetry between the peaks of the wall shear stress in the two half-cycles. They also observed low and high turbulent speed streaks of fluid, responsible for the deviations of the wall shear stress from the laminar values, and a strong deviation of the probability density function of the wall shear stress fluctuations from the normal distribution. In [7], the previous study was extended to include the statistics of the velocity in the boundary layer, through experimental and numerical investigations. It was observed that close to the wall both skewness and flatness are large while at elevations above those corresponding to the local maximum of the streamwise velocity, the skewness is small and the flatness close to 3 as it occurs for a normal distribution.

In the presence of sandy beds, the interaction of asymmetrical and/or skewed waves with the bottom can lead to the appearance of bedforms that may exhibit a degree of asymmetry and this in turn may affect the flow [8].

Due to their relevance for coastal hydro-morphodynamics, a large number of studies investigated ripple formation and evolution (e.g., $[9,10])$. Most of the works however were aimed at predicting their characteristics under sinusoidal oscillatory flows (e.g., [11,12]), while few studies exist on the effects of flow asymmetry on the bed response. Sekiguchi and Sunamura [13] examined the threshold condition for ripple formation under asymmetrical oscillatory flow and found that an increase in bed perturbation decreases the influence of velocity asymmetry on ripple initiation. Testik et al. [14] studied equilibrium profiles of asymmetrical sand ripples that form under nonlinear shoaling waves and found that the equilibrium asymmetric sand ripple profiles can be considered as self-similar. Asymmetric bedforms were studied theoretically by Blondeaux et al. [15] through a weakly nonlinear stability analysis. They found that, depending on wave and sediment characteristics, a flat sandy bottom subjected to an oscillatory flow may lead to asymmetric ripples with the onshore flank of the ripples steeper than the offshore flank. More recently, Petrotta et al. [16] experimentally analyzed the morphodynamic evolution of a sloping sandy bottom starting from a flat bottom condition until the appearance of large amplitude ripples. They observed that, when equilibrium is reached, the ripples show an asymmetrical profile with steeper onshore flanks and gently sloping offshore faces, similar to what was previously found by [15]. However, along the sloping bed, they observed that ripples migrate offshore with a velocity that decreases in time, caused by a net suspended offshore sediment flux. Petrotta et al. [16] attempted to relate migration velocity to asymmetrical flow measured on the sloping bed; however, due to the high sediment suspension close to the bed and the relevant bed mobility, an accurate and reliable flow map could not be recovered. To obtain a reliable map of the flow field, thus filling the gap left by the previous experimental investigation [16], the present work aimed at analyzing the near bed flow generated by waves propagating onto fixed asymmetrical ripples on a sloping bed. In general, a detailed analysis of the flow field in asymmetrical/skewed conditions, such as those that generate on a sloping bed due to shoaling effects, could be useful to shed new light on the near-bed hydrodynamic behavior as well as its repercussions onto sediment transport and related processes. In the present experiments, the near-bed hydrodynamics on a horizontal bed was also acquired to better highlight the differences with sloping bed conditions.

The paper is organized as follows. First, the experimental setup and measurements are presented, and then the experiments are described and analyzed, with particular emphasis on convergence, phase analysis and spatial flow reconstruction. The paper ends with some conclusions.

\section{Experimental Set Up}

Experiments were performed within the wave flume at the Hydraulics Laboratory of Messina University (Italy). The $18 \mathrm{~m}$ long flume has a cross section $0.40 \mathrm{~m} \times 0.80 \mathrm{~m}$, glass walls, and a flat stainless steel bottom (Figure 1). 


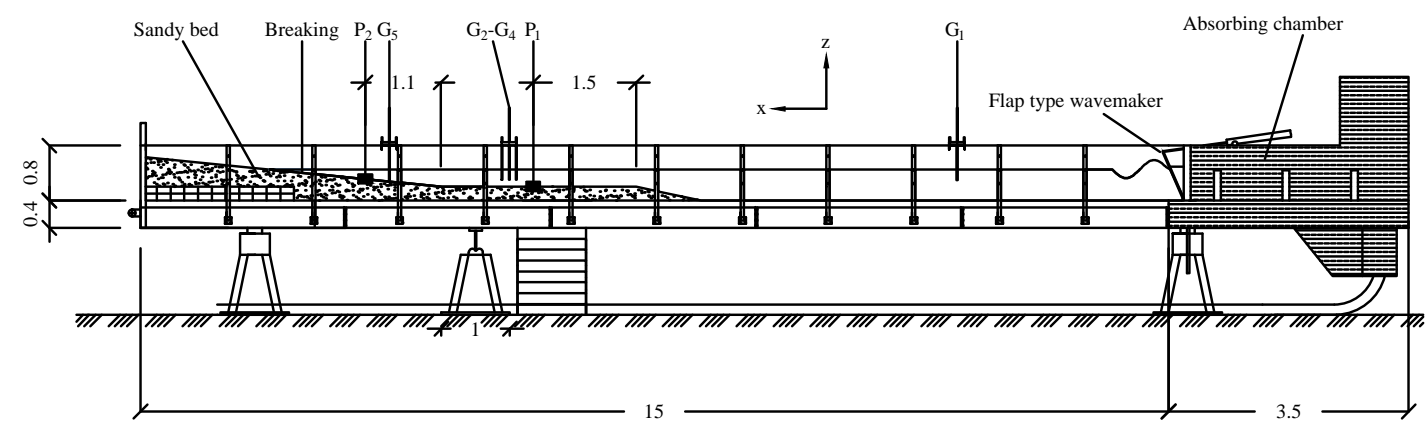

Figure 1. Experimental set up adopted in the present experimental campaign. $P_{1}$ and $P_{2}$ indicate the location of the two ripples subject to hydrodynamic measurements, respectively on the flat and the sloping bed; $G_{1}-G_{5}$ indicate the wave gauge positions along the flume. The $x$-axis of the reference system points in the wave propagation direction while the $z$-axis points upwards.

A flap type wavemaker, driven by a pneumatic system and is electronically controlled, generates both regular and random waves characterized by wave heights up to $0.12 \mathrm{~m}$ and wave periods between 0.5 and $2 \mathrm{~s}$.

Some creased pipe pieces mattresses are placed at the back of the wavemaker to absorb any spurious reflection caused by the flap motion. More details on the facility can be found for example in the works of Liu and Faraci [17], Faraci et al. [18] and Faraci [19].

Starting from a distance of $8 \mathrm{~m}$ from the wavemaker and for the remaining $7 \mathrm{~m}$ length of the flume, the bottom was covered with a layer $0.2 \mathrm{~m}$ thick of uniform sand, with a median grain size $d_{50}=0.25 \mathrm{~mm}$. The last $3.5 \mathrm{~m}$ of wave flume were covered by a 1:10 sloping beach.

The rippled bed was generated by a monochromatic wave characterized by a height $H=0.08 \mathrm{~m}$ and a period $T=1 \mathrm{~s}$ propagating on the layer of sand. The equilibrium condition was reached after the propagation of about 1800 waves (see Figure 2a). Repeatability of bedform formation was checked in a previous work [16]; it was found that the bedform characteristics are well described as a function of the flow mobility number. Later, the flume was dried and the bed was solidified covering the wet sand with two layers of concrete (Figure 2b), carefully sifted in order not to alter the sand grain size and the ripple profiles.

Once the concrete had hardened, two pretty cylindrical ripples, in the following referred to as $P_{1}$ and $P_{2}$, were selected for the hydrodynamic measurements described in the following. The first one was placed $1.5 \mathrm{~m}$ from the beginning of the horizontal sandy bottom (ripple $P_{1}$ in Figure 1), whereas the second one was placed $2.45 \mathrm{~m}$ forward, i.e., $1.1 \mathrm{~m}$ ahead of the beginning of the slope (ripple $P_{2}$ in Figure 1). Ripple $P_{1}$ length $\lambda$ was equal to $4.2 \mathrm{~cm}$ and the height $\eta$ was $0.6 \mathrm{~cm}$, whereas ripple $P_{2}$ length was equal to $6.1 \mathrm{~cm}$ and its height was $0.9 \mathrm{~cm}$. Ripple $P_{1}$ was symmetrical while ripple $P_{2}$ exhibited a small degree of asymmetry, showing a steeper offshore flank. Generally speaking, each ripple shows some degree of randomness in its profile, even though ripple heights and lengths are pretty constant. Because of this characteristic, numerical simulations of the flow field over such a natural shaped bed should be performed including several wavelength in the computational domain. This requirement might lead to high computational costs, which must be carefully evaluated before attempting a numerical study of the flow field.

In the present experiments, nine equally spaced measuring locations $\left(L_{1}-L_{9}\right)$ were considered along each of the two ripples $P_{1}$ and $P_{2}$ (see Figure 2c). A local vertical reference was used, with the zero always located on the fixed rippled bed trough. 


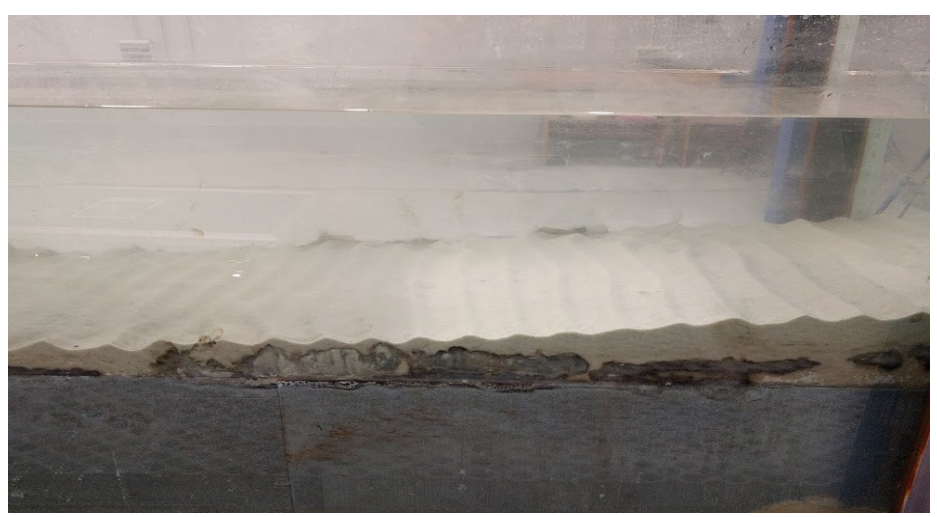

(a)

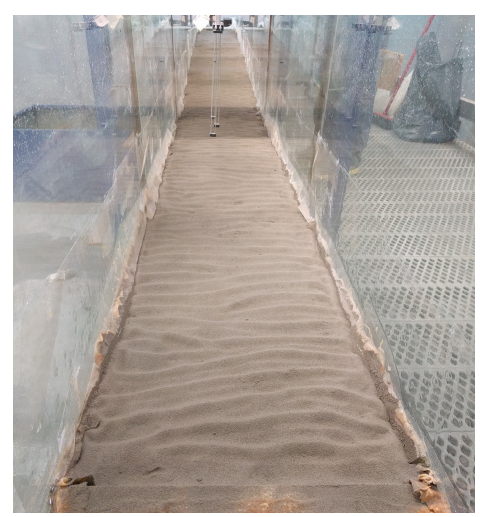

(b)

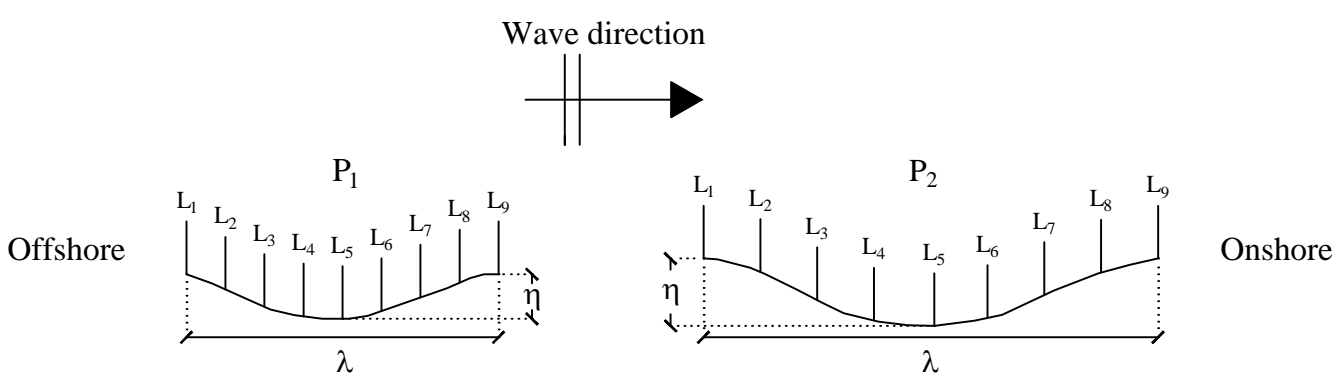

(c)

Figure 2. The rippled bed: (a) picture of the bed at the equilibrium condition; (b) picture of the fixed bed after the sieving process; and (c) ripples $P_{1}$ (flat bed) and $P_{2}$ (sloping bed). $L_{1}-L_{9}$ indicate the positions of the nine vertical measuring locations at ripples $P_{1}$ and $P_{2}, \lambda$ being the ripple wavelength

\section{Measurements}

\subsection{Water Surface Elevation}

Five resistive wave gauges allowed the measurements of wave characteristics throughout the wave flume. The first gauge $\left(G_{1}\right)$ was placed $3.25 \mathrm{~m}$ off the wavemaker to measure fully developed waves, the three gauges $G_{2}, G_{3}$, and $G_{4}$ were located on the horizontal sand layer and spaced properly to allow the application of the Mansard and Funke [20] method to measure the wave reflection along the flume. Measurements showed that wave reflection along the flume was generally between $15 \%$ and $20 \%$ of the incident wave. In the largest wave periods, reflection grew up to $30 \%$. The gauge $G_{5}$ was placed on the sloping beach, where the waves shoal.

\subsection{Hydrodynamics}

Velocity profiles were acquired by means of a Vectrino Profiler (Nortek As.) at the nine measuring locations $\left(L_{1}-L_{9}\right)$ along the ripples $P_{1}$ and $P_{2}$, as mentioned above.

Profiles were obtained by vertically overlapping the velocity profiles of two adjacent measurement stations by the amount $\Delta z=1 \mathrm{~cm}$. This was necessary to remove data collected outside the region between approximately 43 and $61 \mathrm{~mm}$ below the transceiver, which, according to Thomas et al. [21], were marked as not sufficiently reliable.

Velocities were measured throughout the water column, i.e., from the bottom up to about $4 \mathrm{~cm}$ below the wave through, at $P_{1}$, and up to an elevation of about $10 \mathrm{~cm}$ at $P_{2}$ positions. Measurements started three minutes after the wavemeaker launch in order to reach a stable flow condition. Then, the flow field at each position was acquired for $2 \mathrm{~min}$. This operation took about $20 \mathrm{~min}$ on the sloping 
bed, where the water depth was $0.145 \mathrm{~m}$, and forty minutes on the horizontal plane, where the water depth was $0.245 \mathrm{~m}$. At the end, the wavemaker was stopped.

In one of the tests, Vectrino Profiler acquired data for $10 \mathrm{~min}$ at each measuring station in order to check the velocity statistics convergence. In this case, the Vectrino Profiler started measuring on sync with the wavemaker launch. In this case, since the velocity acquisition started from still water, the transient condition had to be filtered out during the signal processing, thus data collected throughout the first 3 min were not analyzed. During all the other tests, the wavemaker was not stopped and started, thus no transient conditions were formed.

The reliability of the measured velocities is related to two parameters, namely Correlation (COR) and Signal to Noise Ratio (SNR). COR is a measure of signal quality in percent, while SNR expresses the signal amplitude relative to the instrument noise level, in $\mathrm{dB}$. Two acceptance thresholds were adopted, according to Van Der A et al. [22], Yoon and Cox [23]: $C O R \geq 90$ and $S N R \geq 30$ near the weak spot, i.e., from $50 \mathrm{~mm}$ to $65 \mathrm{~mm}$ below the transceiver, and $S N R \geq 20$ elsewhere. Non-reliable data were then replaced by a linear interpolation. Finally, data were despiked by means of the Goring and Nikora [24] method. To improve data integrity some talc powder was dispersed close to the probe head to increase the number of scatters in the sampling volume. Moreover, in one of the performed tests, the cell size parameter was initially set equal to $1 \mathrm{~mm}$ and then to $2 \mathrm{~mm}$. However, comparing the two obtained profiles, results were pretty similar, thus a cell size equal to $1 \mathrm{~mm}$ was adopted for the the other tests.

A zero up-crossing method was adopted to split the cleaned signal and to calculate the ensemble averaged velocities. Zeros were identified within the velocity signal except during a long lasting test where zeros were determined from the elevation measured by the resistive wave gauge closest to the Vectrino, i.e., G4. Finally, a matrix containing in each column a velocity fluctuation throughout a period and in each row a phase was arranged. Periods longer than $1.03 T$ or shorter than $0.97 T$, where $T$ is the reference period (generally $2-5 \%$ ), were rejected.

\section{Experiments}

The experimental campaign consisted of the nine tests, named T1-T9 (see Table 1). Velocities measured along the two ripples $P_{1}$ and $P_{2}$, placed, respectively, on the horizontal bed and on the sloping bed, were analyzed in order to gain insights on the effect of the sloping bed.

During the experiments the water depth $d$ was kept fixed and equal to $0.245 \mathrm{~m}$ over ripple $P_{1}$ $\left(d=0.145 \mathrm{~m}\right.$ at $\left.P_{2}\right)$.

The main hydrodynamics parameters considered in the present experimental campaign are as follows.

- The semi-orbital amplitude of the fluid particles outside the boundary layer:

$$
A=\frac{U_{\infty}}{\omega}
$$

- The wave induced velocity just above the bottom boundary layer:

$$
U_{\infty}=\frac{H \omega}{2 \sinh (k d)}
$$

- The wavenumber:

$$
k=\frac{2 \pi}{L}
$$

In the above equations, $H$ indicates the wave height, $L$ is the wavelength, $\omega$ is the angular frequency equal to $2 \pi / T$, and $T$ is the wave period, as mentioned above. Ripple height $\eta$ and wavelength $\lambda$ were not included as they were fixed in the present experimental campaign, their values were reported at the end of Section 2. 
In Table 1, a summary of the experimental conditions and of the main hydrodynamics parameters is reported. In particular, the first column indicates the test name, the second and third columns report the wave characteristics, namely the wave height $H$ measured by the gauge $G_{1}$ and period $T$, finally Columns 4 and 5 report the value of the semi-orbital amplitude while Columns 6 and 7 report the values of the flow Reynolds number, measured at both $P_{1}$ and $P_{2}$, computed as:

$$
R e=\frac{U_{\infty} A}{v}
$$

$v$ being the kinematic viscosity of water.

Table 1. Experimental conditions and main Hydrodynamics parameters.

\begin{tabular}{ccccccc}
\hline \multirow{2}{*}{ Test Name } & \multirow{2}{*}{$\mathbf{H}[\mathrm{cm}]$} & \multirow{T}{*}[\mathbf{s}]{} & \multicolumn{2}{c}{$\boldsymbol{A}[\mathrm{cm}]$} & \multicolumn{2}{c}{$\boldsymbol{R} \boldsymbol{e}$} \\
& & & $\boldsymbol{P}_{\mathbf{1}}$ & $\boldsymbol{P}_{\mathbf{2}}$ & $\boldsymbol{P}_{\mathbf{1}}$ & $\boldsymbol{P}_{\mathbf{2}}$ \\
\hline T1 & 2.54 & 1.26 & 1.27 & 1.82 & 808 & 1655 \\
T2 & 8.13 & 1.01 & 2.78 & 4.34 & 4825 & 11,692 \\
T3 & 6.27 & 0.84 & 1.42 & 2.48 & 1504 & 4611 \\
T4 & 4.36 & 1.26 & 2.19 & 3.15 & 2381 & 4948 \\
T5 & 8.70 & 1.01 & 2.98 & 4.64 & 5525 & 13,389 \\
T6 & 9.05 & 0.84 & 2.05 & 3.58 & 3133 & 9607 \\
T7 & 13.05 & 0.84 & 2.95 & 5.17 & 6515 & 19,977 \\
T8 & 8.67 & 1.01 & 2.97 & 4.62 & 5487 & 13,297 \\
T9 & 5.86 & 1.26 & 2.94 & 4.23 & 4302 & 8939 \\
\hline
\end{tabular}

\section{Analysis of the Experimental Results}

The hydrodynamics induced by waves propagating over a fixed rippled bed is discussed in the present section where the velocities measured throughout T1-T9 tests are shown.

As mentioned above, for each experiment, the duration of acquisition was 2 min except for test T9. In this test, the duration of acquisition was increased to $10 \mathrm{~min}$ in order to check the convergence of the velocity statistics.

In the following, period averaged quantities are indicated by the overbar - , while phase averaged quantities by $<>$.

\subsection{Velocity Profiles and Statistics}

Figure 3 shows the velocity measured by the third cell from the top of the control volume of the Vectrino Profiler during T9 test at the location $L_{2}, x / \lambda=1 / 8$ from ripple crest (see Figure 2c) at an elevation of about $2.5 \mathrm{~cm}(z / d=0.10)$.

Figure 3 a shows the velocity acquired after $3 \mathrm{~min}$ from the launch of the wavemaker for a time span equal to one period. The four beams of the Vectrino Profiler measured the velocity components $U, V, W_{1}$ and $W_{2}$ along the direction of wave propagation $x$, the transverse direction $y$ and the vertical direction $z$, respectively. Throughout the experimental campaign, the velocity was analyzed and the phase averaged velocities shown in Figure $3 \mathrm{~b}$ were obtained. It is worth pointing out that, as expected, no reliable difference among the two vertical velocities $W_{1}$ and $W_{2}$ measured along the $z$ direction was detected, thus in the rest of the paper only the $W_{1}$ component is plotted and referred to as $W$.

Figure $3 \mathrm{c}$ reports the velocity acquired within an analogous time span along the sloping bed and Figure $3 \mathrm{~d}$ the phase averaged velocity. At $P_{2}$, wave shape become skewed and asymmetric and this, in turn, affects the velocity. Thus (as shown in Figure $3 \mathrm{c}, \mathrm{d}$ ), velocity becomes asymmetric at $P_{2}$, with sharp crests and broad troughs. Moreover, the negative half wavelength is wider than the positive one giving rise to a velocity skewness. Note that the position along the ripple profile and the elevation from the bed are the same in both cases. 


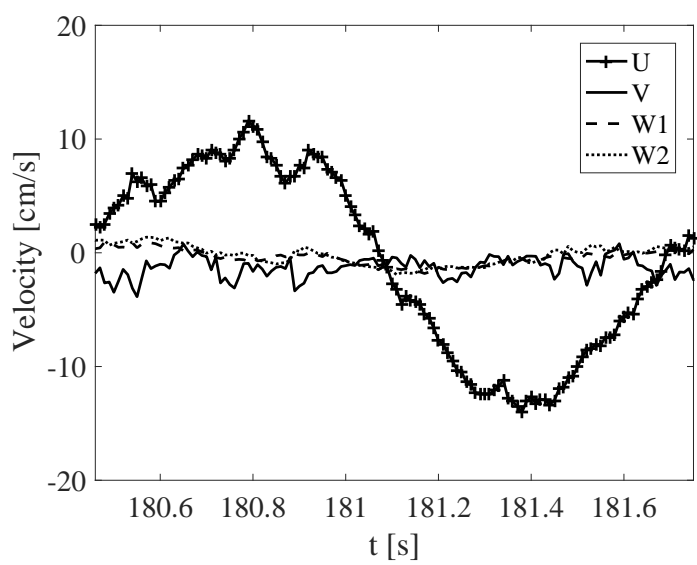

(a)

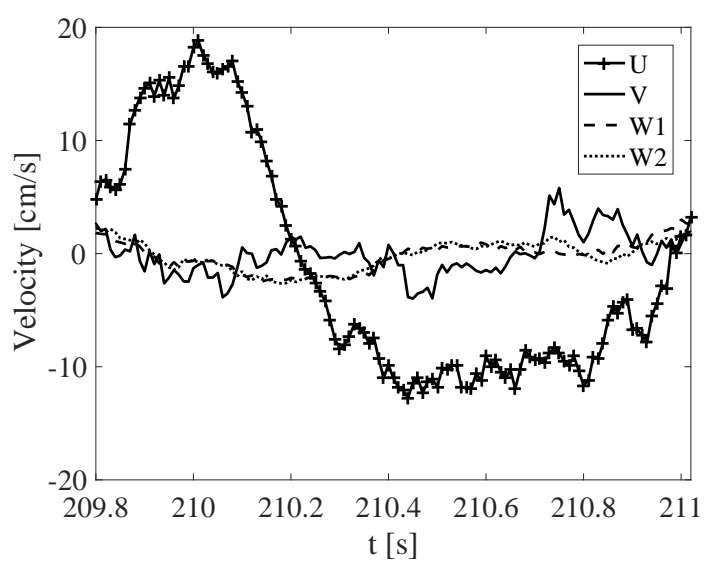

(c)

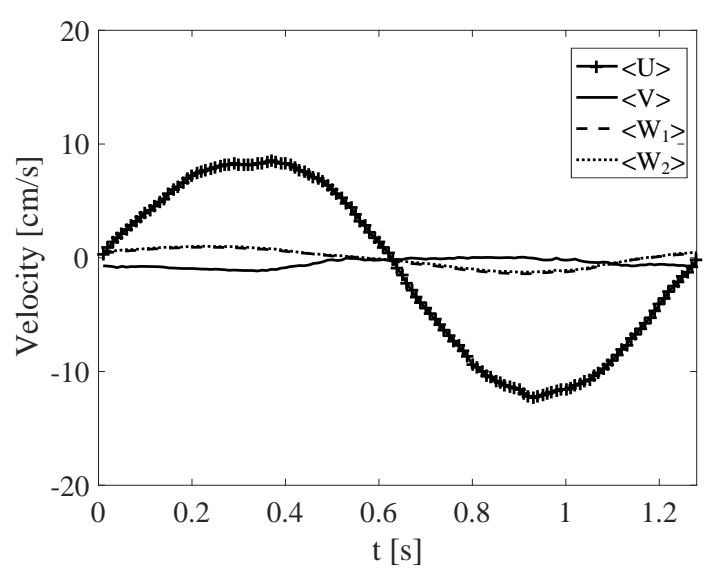

(b)

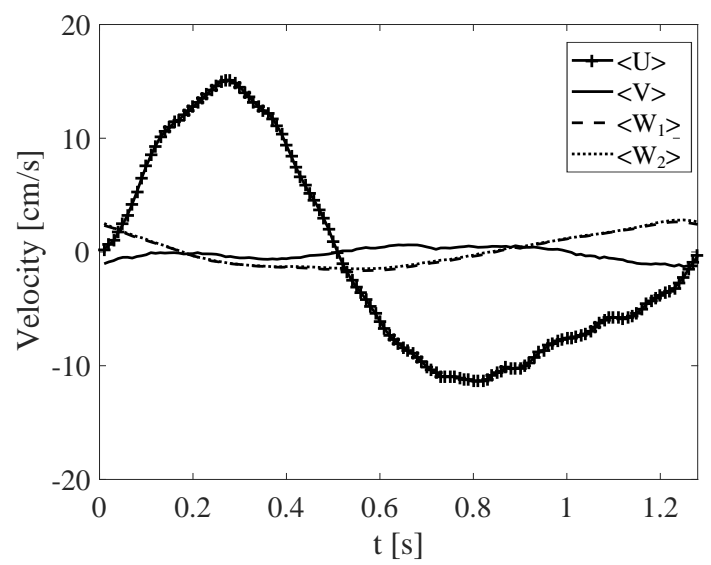

(d)

Figure 3. T9 test $(H=0.06 \mathrm{~m}, T=1.26 \mathrm{~s})$, velocities measured at location $L_{2}$, at the elevation $z / d=0.10$ : (a) Vectrino Profiler velocity just after the transient condition at $P_{1} ;(\mathbf{b})$ phase averaged velocity at $P_{1}$;

(c) Vectrino Profiler velocity at $P_{2}$; and (d) phase averaged velocity at $P_{2}$.

As mentioned above, during experiment $T 9$, the acquisition time was set to $10 \mathrm{~min}$, which was longer with respect to the other experiments in order to analyze the convergence of the period averaged velocity as the number of flow cycles increases (see Figures 4-6). The first $3 \mathrm{~min}$ of the measured velocity were thrown out and not further examined as affected by the flow transient. Thus, each plot illustrates by means of different markers the statistics $1,3,5$, and 7 min after the beginning of the time interval considered in the analysis.

The convergence of the period averaged velocity profiles measured during $T 9$ test both above the horizontal bed (ripple $P_{1}$ ) and the sloping bed (ripple $P_{2}$ ) was analyzed. Figures 4 and 5 show, respectively, the velocity component $U$ in the direction of the wave propagation $x$ and the velocity component $W$ in the vertical direction $z$. Velocities were measured at nine equally spaced locations along both ripples, as represented in Figure 2c. Nevertheless, for the sake of brevity, only the two locations $L_{2}(x / \lambda=1 / 8)$, along the offshore flank, and $L_{8}(x / \lambda=7 / 8)$, along the onshore flank, were reported. 


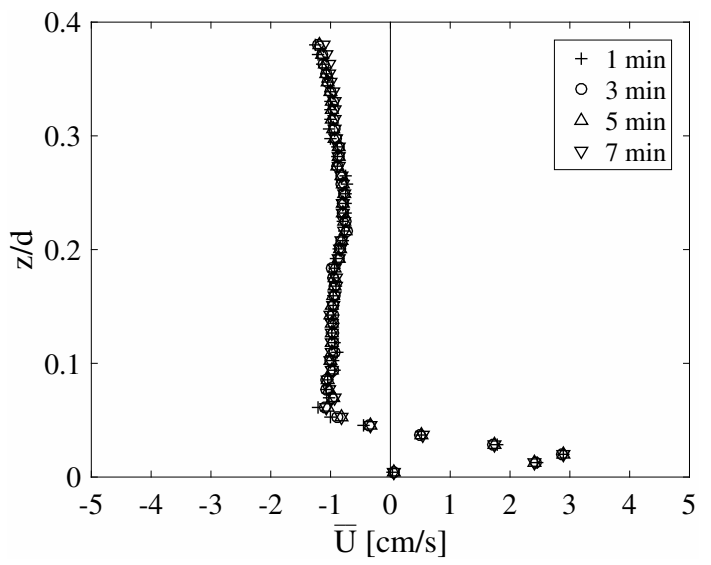

(a)

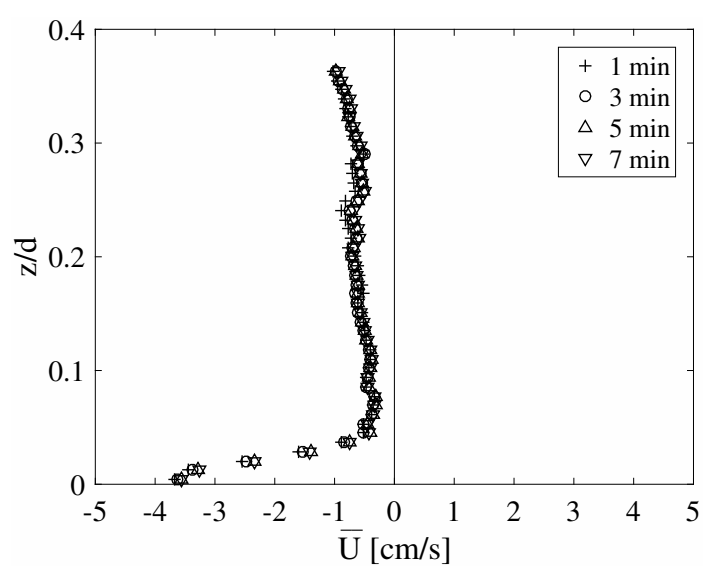

(c)

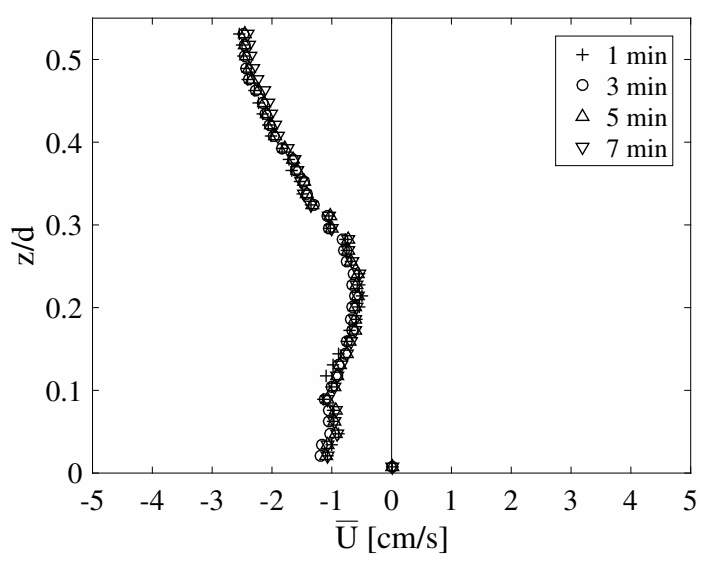

(b)

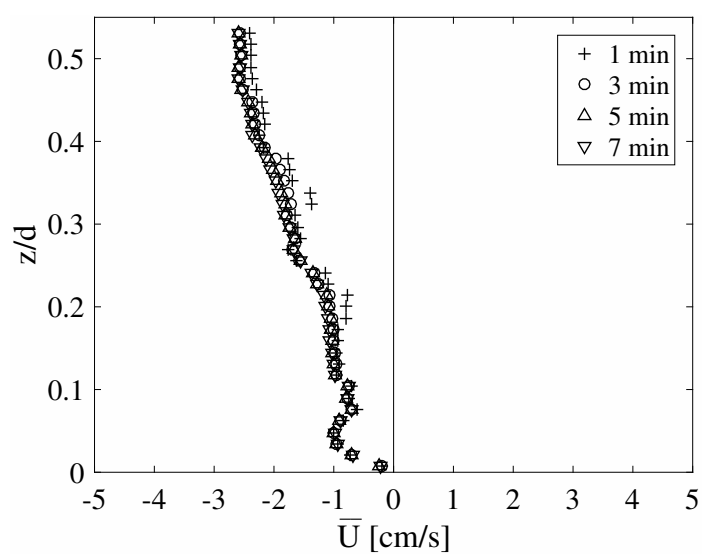

(d)

Figure 4. $T 9$ test $(H=5.86 \mathrm{~m}, T=1.26 \mathrm{~s})$, period averaged $U$ velocity profiles in the $\mathrm{x}$ direction evaluated on the basis of measurement with durations ranging from 1 to $7 \mathrm{~min}$ : (a) $P_{1}, L_{2}$; (b) $P_{2}, L_{2}$; (c) $P_{1}, L_{8} ;$ and (d) $P_{2}, L_{8}$ (see Figure 2 c).

Period averaged velocities quickly reach a stable condition. Indeed, velocity profiles measured after 3, 5 and 7 min clearly overlap. Only profiles at 1 min slight differ from the others, particularly at low velocities. Thus, as mentioned above, the period averaged velocity was computed using at least $2 \mathrm{~min}$.

Outer flow velocities $(z / d>0.05)$ in the direction of the wave propagation $x$ are slightly negative ( $\bar{U}<-1 \mathrm{~cm} / \mathrm{s}$ ) at both $P_{1}, L_{2}$ and $P_{1}, L_{8}$ (Figure $\left.4 \mathrm{a}, \mathrm{c}\right)$. It can be observed that because of the undertow the mean velocity is mostly negative at $P_{1}$ both at $L_{2}$ and $L_{8}$. However, near to the wall a boundary layer is present in which at $P_{1}$ the velocity is onshore directed at $L_{2}$ while at $L_{8}$ it is offshore directed. In determining the mean velocity direction in the boundary layer, there are two main mechanisms interacting with each other in a complex way. The first mechanism is due to the spatial variability induced by the waves, which generates a streaming in the same direction of wave propagation [25]. The second mechanism is due to the asymmetry of the turbulence during the two half cycles, which under skewed or asymmetric waves produces a steady streaming in the offshore direction [26].

Along the sloping bed at $z / d>0.05$, the undertow current is larger than that on the plane bed $\left(P_{1}\right)$. Such a return current extended to the horizontal bed and caused the period averaged outer flow velocities to become negative, as previously observed. 


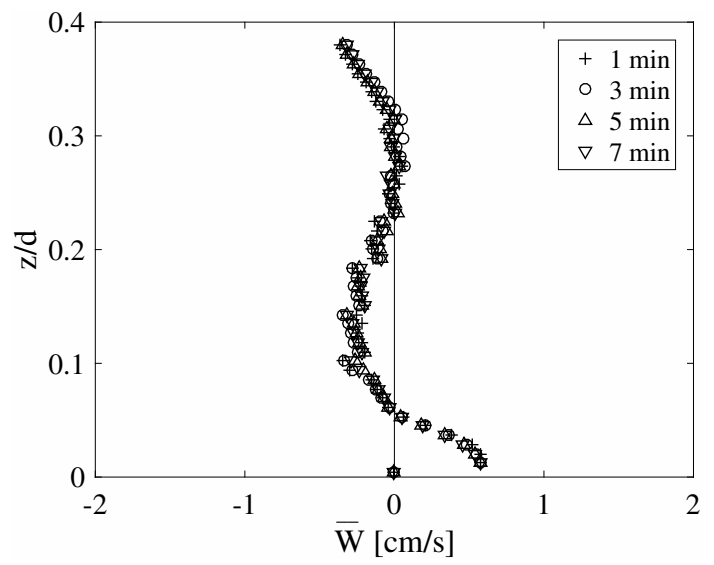

(a)

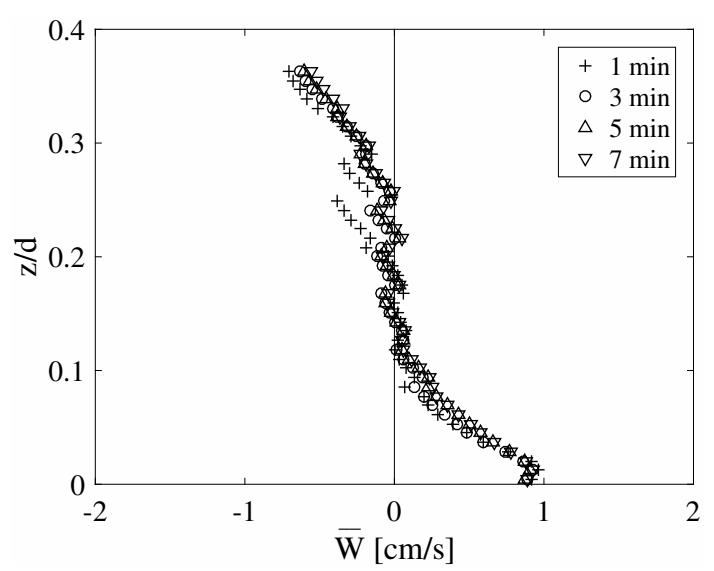

(c)

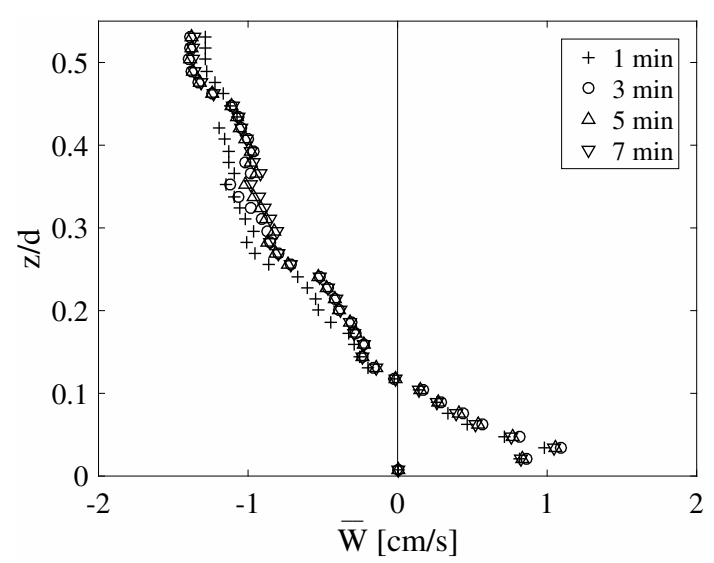

(b)

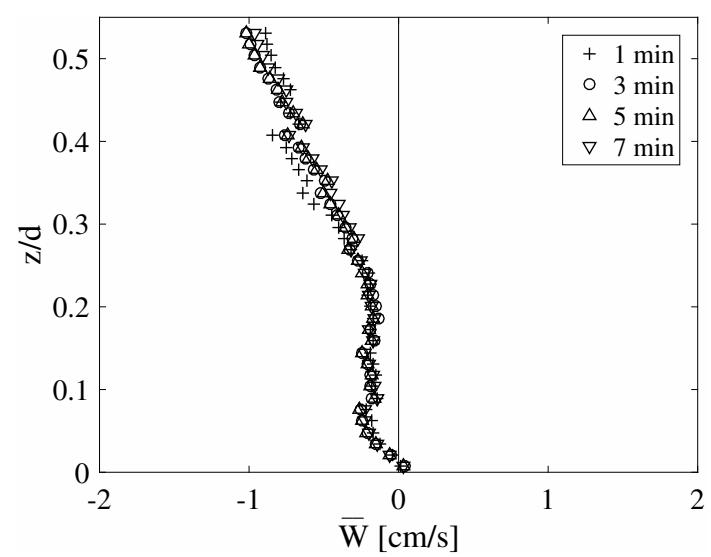

(d)

Figure 5. T9 test $(H=5.86 \mathrm{~m}, T=1.26 \mathrm{~s})$, period averaged $W$ velocity profiles in the $\mathrm{z}$ direction evaluated on the basis of measurement with durations ranging from 1 to $7 \mathrm{~min}$ : (a) $P_{1}, L_{2}$; (b) $P_{2}, L_{2}$; (c) $P_{1}, L_{8} ;$ and (b) $P_{2}, L_{8}$ (see Figure 2 c).

Figure 6 shows the standard deviation $S$, skewness $s_{k}$ and kurtosis $k$ of the horizontal velocity profiles at both positions $P_{1}$ and $P_{2}$ for the $L_{2}$ measuring station.

Given $U_{i}$ the observed velocity and $\langle U\rangle$ its phase averaged value, considering that the acquired velocities are equispaced in time, the aforementioned statistics could be expressed as:

$$
\begin{aligned}
S & =\sqrt{\frac{1}{n-1} \sum_{i=1}^{n}\left(U_{i}-<U>\right)^{2}} \\
s_{k} & =\frac{\frac{1}{n} \sum_{i=1}^{n}\left(U_{i}-<U>\right)^{3}}{\left(\sqrt{\frac{1}{n} \sum_{i=1}^{n}\left(U_{i}-<U>\right)^{2}}\right)^{3}} \\
k & =\frac{\frac{1}{n} \sum_{i=1}^{n}\left(U_{i}-<U>\right)^{4}}{\left(\frac{1}{n} \sum_{i=1}^{n}\left(U_{i}-<U>\right)^{2}\right)^{2}}
\end{aligned}
$$

$n$ being the number of data in the series. In the present work, all the aforementioned statistics were evaluated for each phase and then they were period-averaged. The standard deviation converged 
to a stable value in less than 3 min almost throughout the investigated water depth both along the horizontal bed (Figure 6a) and on the sloping bed (Figure 6b). At both positions, the standard deviation of the outer flow velocities was pretty constant between $z / d=0.35$ and $z / d=0.1$ where velocities started to increase due to the undertow. Near the bed, $\mathrm{S}$ increases because of turbulent fluctuations. measured above the ripple stoss flank.

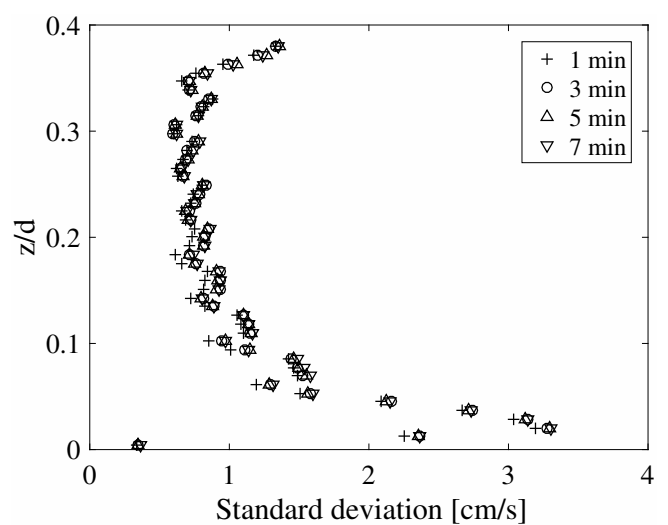

(a)

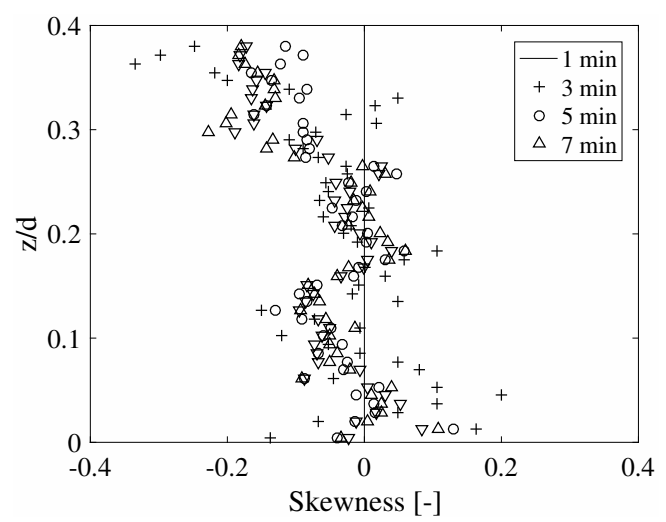

(c)

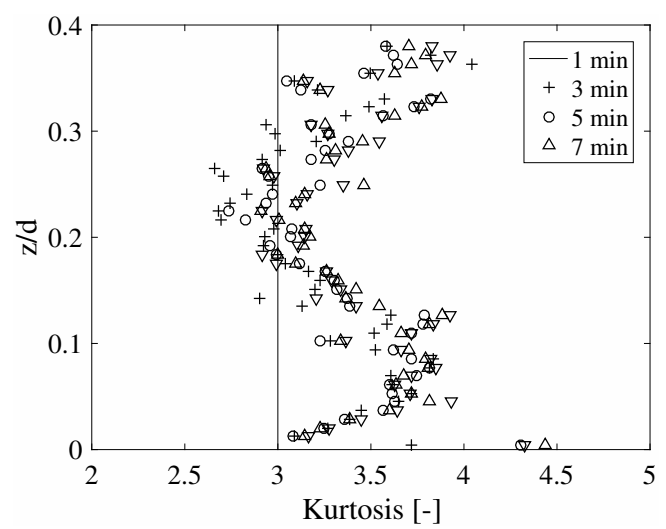

(e)

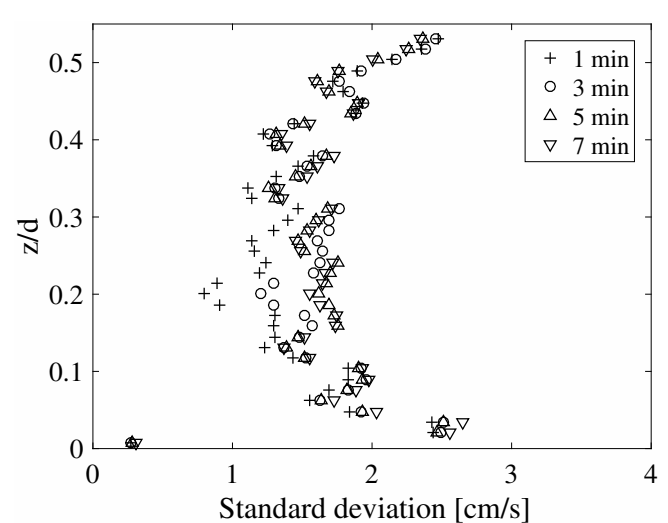

(b)

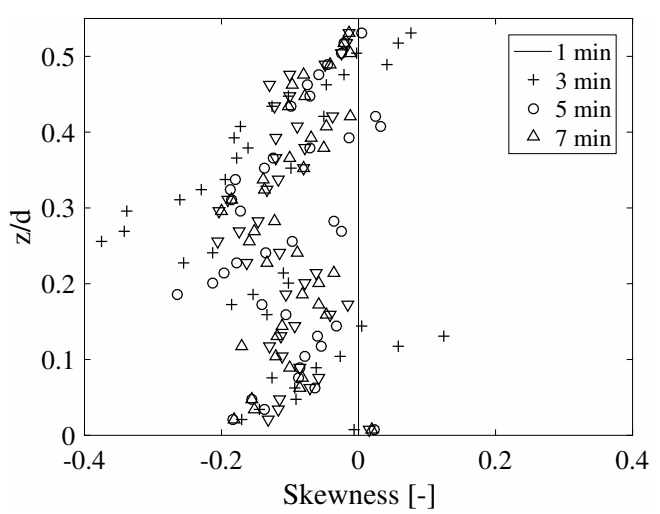

(d)

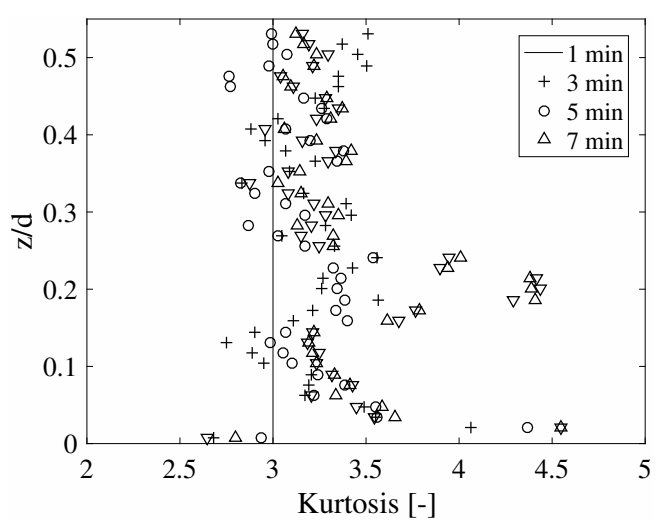

(f)

Figure 6. $T 9$ test $(H=5.86 \mathrm{~m}, T=1.26 \mathrm{~s})$, velocity statistics profiles convergence: (a) standard deviation at $P_{1}, L_{2} ;(\mathbf{b})$ standard deviation at $P_{2}, L_{2} ;$ (c) skewness at $P_{1}, L_{2} ;(\mathbf{d})$ skewness at $P_{2}, L_{2} ;(\mathbf{e})$ kurtosis at $P_{1}, L_{2}$; and (f) kurtosis at $P_{2}, L_{2}$.

In the central part of the profiles, the standard deviation at $P_{1}$ was smaller than at $P_{2}$ where the orbital velocity increased due to the wave asymmetry. However, the steady offshore directed 
currents increased wave skewness, thus the negative half-period became considerably longer than the positive one and, in turn, the period averaged velocity $\bar{U}$ became negative. Since the negative half-period was considerably longer than the positive one, the dispersion of the velocities from their mean value decreased.

Both skewness and kurtosis required $5 \mathrm{~min}$ to reach a stable condition. The depth averaged value of the skewness profiles was about zero along the horizontal bed (Figure $6 \mathrm{c}$ ) and about -0.1 along the sloping bed (Figure $6 \mathrm{~d}$ ). This occurrence confirms that the velocity is symmetrically distributed at $P_{1}$, whereas it became asymmetric at $P_{2}$. There, the velocity distribution has a long negative tail, throughout the water depth, whereas at $P_{1}$ this phenomenon occurs only above $z / d>0.3$.

Figure 6e shows that the kurtosis varies between 3 and 3.5, thus it take values of $k$ close to those of a normal distribution. At $P_{1}$, a value of 3 was observed at the bottom and at $z / d \sim 0.2$. Elsewhere, kurtosis was higher, thus higher velocities (in modulus) were reached more frequently due to the asymmetrical and skewed nature of the flow along the water column. At $P_{2}$, the skewed and asymmetric wave produced the increase of the high velocities recurrence throughout the water depth; thus, kurtosis was almost constantly equal to 3.3 (see Figure 6f). Furthermore, few peaks appeared within kurtosis profiles.

\subsection{Phase Analysis of Velocities and Turbulent Characteristics}

The phase averaged statistics were evaluated at nine equally spaced locations, but, for the sake of brevity, only profiles at the aforementioned $L_{2}$ and $L_{8}$ locations are here reported. Figures 7 and 8 show the phase averaged velocity $U$ and $W$ profiles above the two ripples $P_{1}$ and $P_{2}$, respectively.

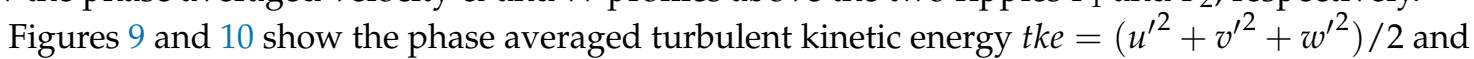
the phase averaged Reynolds stress $\overline{u^{\prime} v^{\prime}}$ profiles above the two ripple flanks, being $u^{\prime}, v^{\prime}$ and $w^{\prime}$ the turbulent velocities, respectively, along $x, y$ and $z$. Turbulent fluctuations were measured along the two ripples $P_{1}$ and $P_{2}$ during the experiment $T_{9}$. Sixty-four equally spaced phases per period were identified but only six phases were sketched, namely $1 / 2 \pi, \pi, 3 \pi / 2$ and $2 \pi$, together with the phases where the depth-averaged velocity reached its maximum and its minimum. The period-averaged avg profile is also plotted.

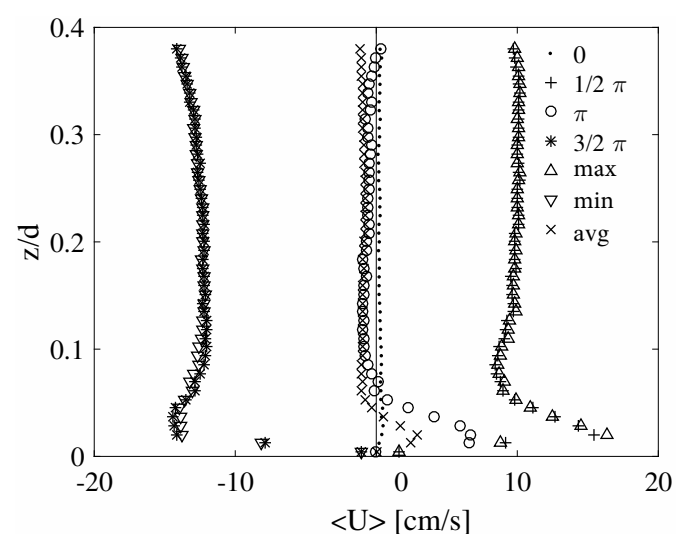

(a)

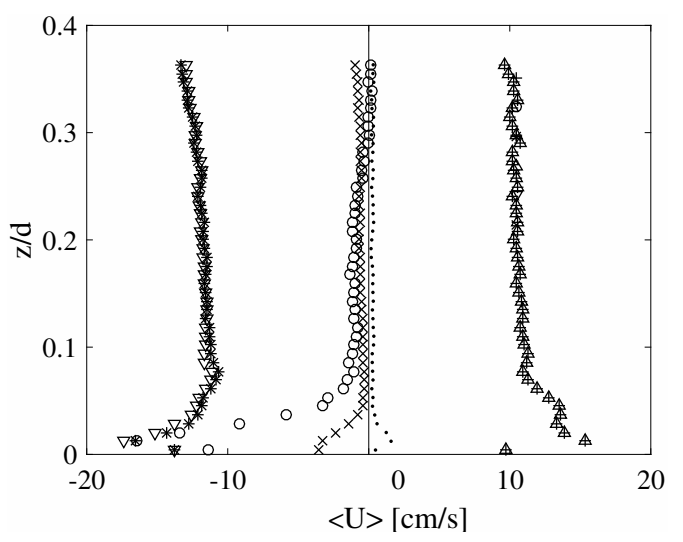

(b)

Figure 7. Cont. 


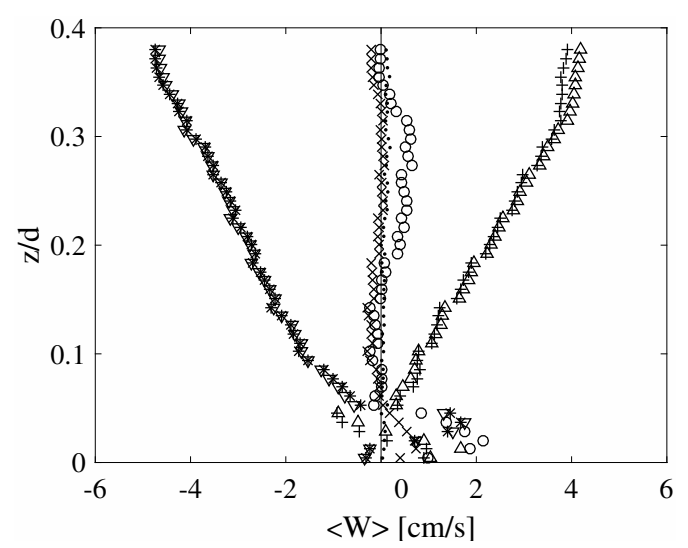

(c)

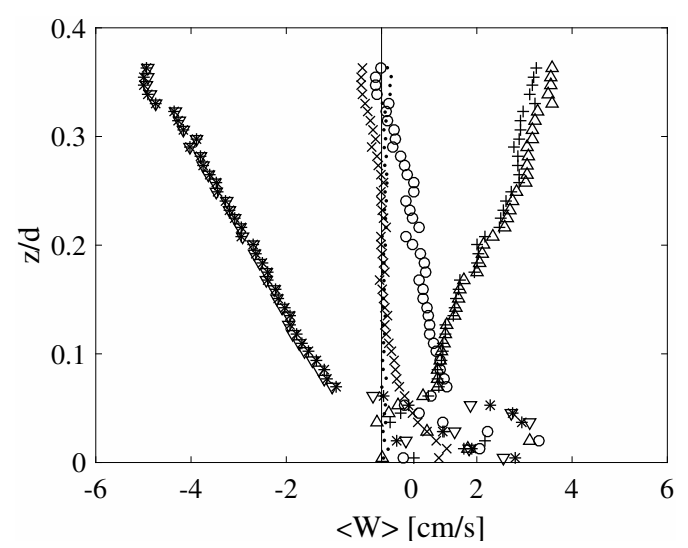

(d)

Figure 7. $T 9$ test $(H=5.86 \mathrm{~m}, T=1.26 \mathrm{~s})$, velocity phase analysis at $P_{1}$ : (a) $U$ velocity profile at $L_{2} ; \max =17 / 32 \pi, \min =47 / 32 \pi ;\left(\right.$ b) $U$ velocity profile at $L_{8} ; \max =16 / 32 \pi, \min =46 / 32 \pi$; (c) $W$ velocity profile at $L_{2} ; \max =13 / 32 \pi, \min =49 / 32 \pi$; and (d) $W$ velocity profile at $L_{8} ; \max =$ $14 / 32 \pi, \min =49 / 32 \pi$.

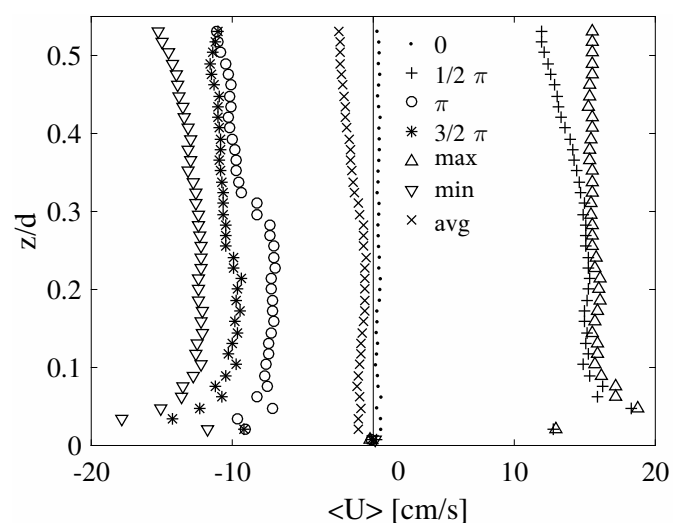

(a)

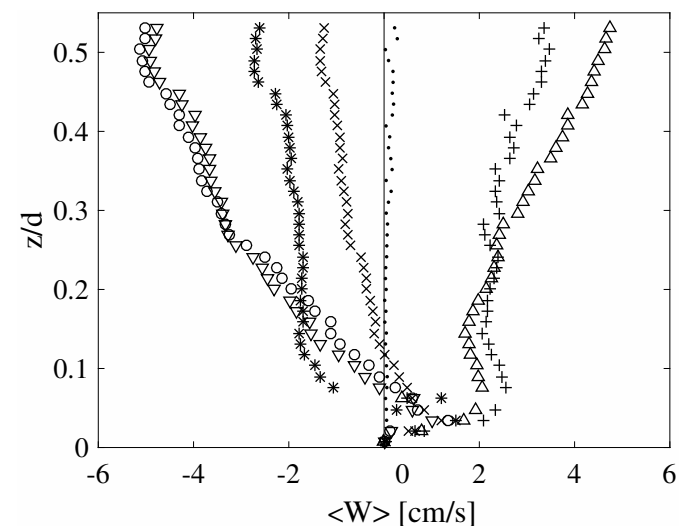

(c)

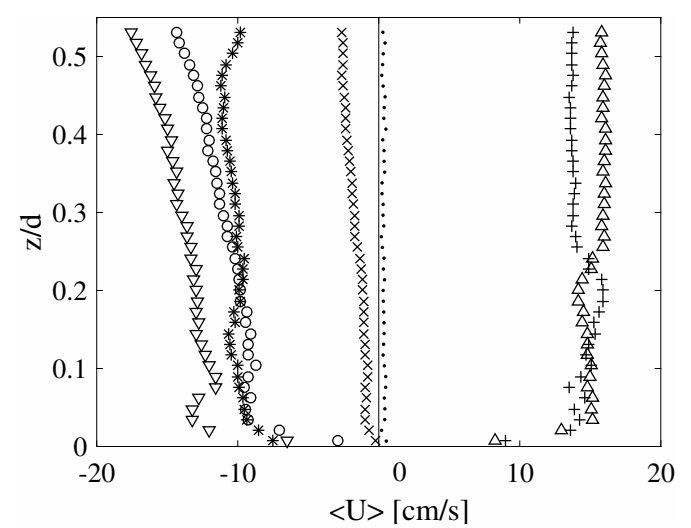

(b)

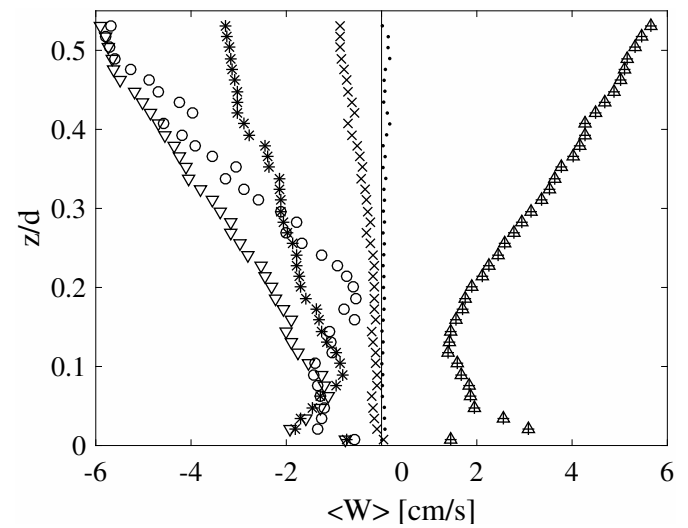

(d)

Figure 8. T9 test $(H=5.86 \mathrm{~m}, T=1.26 \mathrm{~s})$, velocity phase analysis at $P_{2}$ : (a) $U$ velocity profile at $L_{2} ; \max =13 / 32 \pi, \min =40 / 32 \pi ;\left(\right.$ b) $U$ velocity profile at $L_{8} ; \max =13 / 32 \pi, \min =38 / 32 \pi$; (c) $W$ velocity profile at $L_{2} ; \max =13 / 32 \pi, \min =34 / 32 \pi$; and (d) $W$ velocity profile at $L_{8} ; \max =$ $16 / 32 \pi, \min =37 / 32 \pi$.

The velocity profiles of $U$ and $W$ are rather symmetrical above the horizontal bed both at $L_{2}$ and at $L_{8}$. Looking at $P_{1}$ profiles, Figure $7 \mathrm{a}-\mathrm{d}$, it could be observed that the modulus of the velocity at 
$1 / 2 \pi$ phase is similar to the modulus of the velocity at $3 / 2 \pi$ phase in the central part of the water column. More important differences arise close to the bed, where, due to the constraints imposed by the ripple flanks, $<U>$ overshooting at $L_{2}$ at the phase $1 / 2 \pi$ is similar to the one at $L_{8}$ at the phase $3 / 2 \pi$, and, analogously, near bottom flow at $L_{2}$ at the phase $3 / 2 \pi$ is similar the one at $L_{8}$ at the phase $1 / 2 \pi$. In the upper part of the water column, the absolute values of the minimum velocities are slightly higher than maximum ones due to the presence of the undertow.

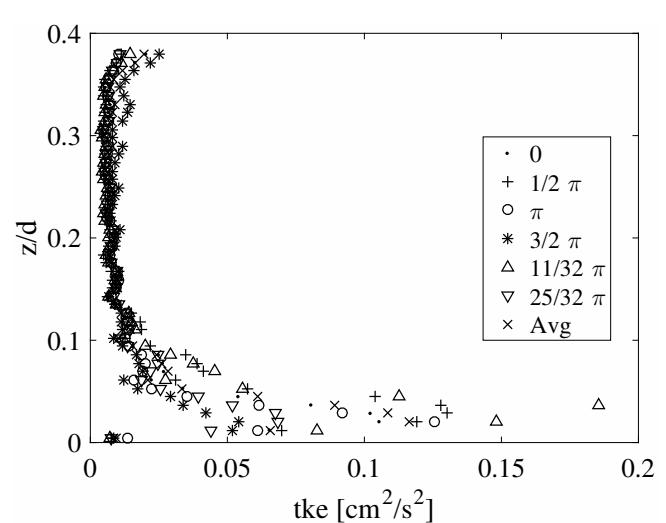

(a)

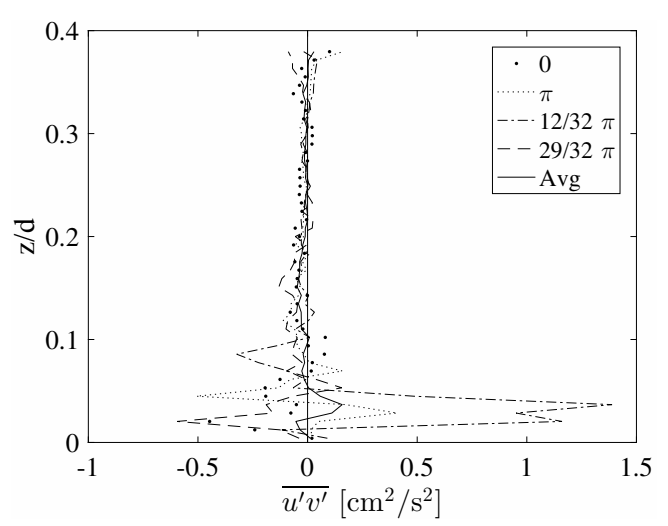

(c)

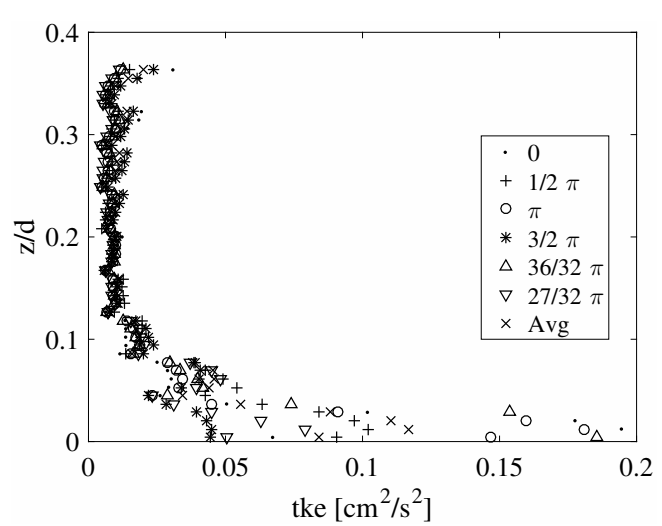

(b)

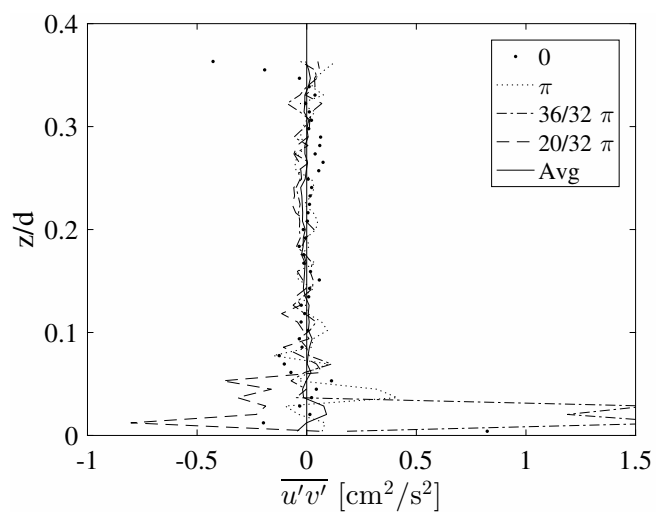

(d)

Figure 9. $T 9$ test $(H=5.86 \mathrm{~m}, T=1.26 \mathrm{~s})$, turbulence phase analysis: (a) tke profile at $P_{1}, L_{2} ;(\mathbf{b})$ tke profile at $P_{1}, L_{8} ;$ (c) Reynolds stress profile at $P_{1}, L_{2} ;$ and (d) Reynolds stress profile at $P_{1}, L_{8}$.

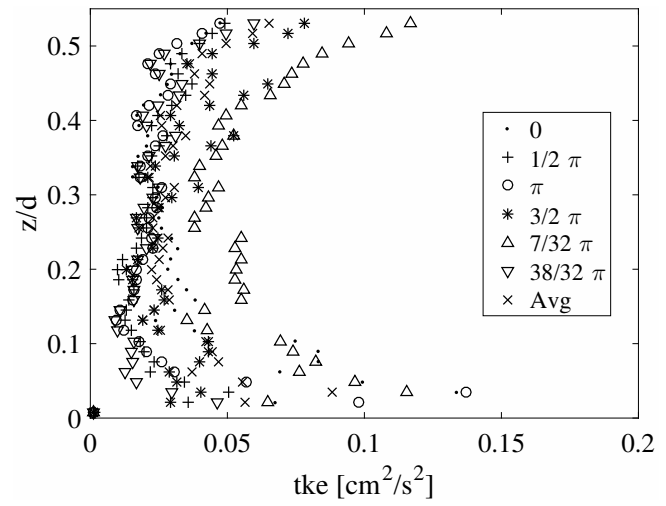

(a)

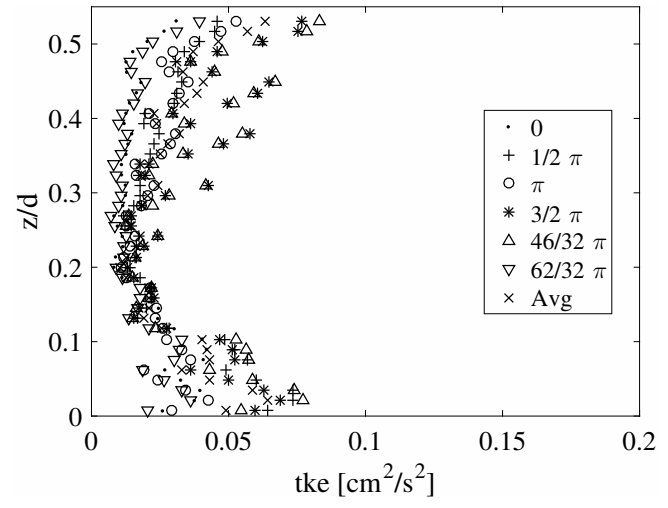

(b)

Figure 10. Cont. 


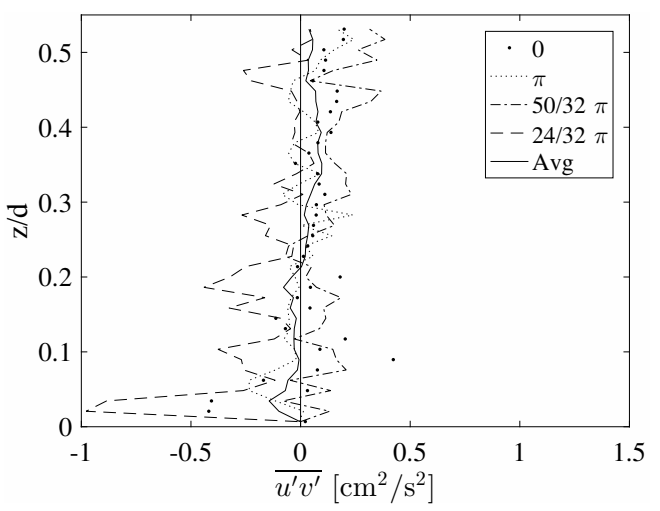

(c)

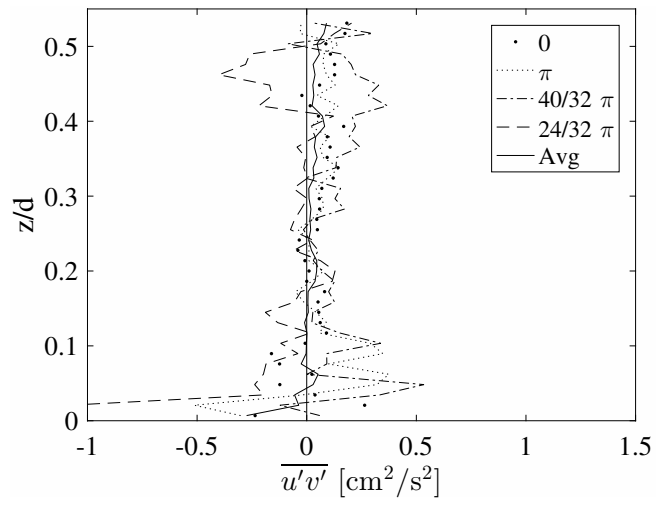

(d)

Figure 10. $T 9$ test $(H=5.86 \mathrm{~m}, T=1.26 \mathrm{~s})$, turbulence phase analysis: $(\mathbf{a})$ tke profile at $P_{2}, L_{2} ;(\mathbf{b})$ tke profile at $P_{2}, L_{8} ;$ (c) Reynolds stress profile at $P_{2}, L_{2}$; and (d) Reynolds stress profile at $P_{2}, L_{8}$.

Moreover, the $\langle U>$ phase-averaged velocity reaches its maximum at $1 / 2 \pi$ phase (Figure $7 b$ ) or slightly after (Figure 7a) and its minimum slight before $3 / 2 \pi$ phase. The $<W>$ phase-averaged velocity reaches its maximum slight before $1 / 2 \pi$ phase and its minimum slight after $3 / 2 \pi$ phase (Figure $7 \mathrm{c}, \mathrm{d}$ ). The vertical component of the velocity is slightly more asymmetrical than the horizontal component, as can be detected by looking the $\langle W\rangle$ velocities measured at 0 and at $\pi$ phases. However, except that near the bottom where ripple shape made flow asymmetric, both $\langle U\rangle$ and $<W>$ velocity profiles are negligible at 0 phase and smaller than $1 \mathrm{~cm} / \mathrm{s}$ at $\pi$ phase throughout the water depth.

At the bottom $(z / d<0.1),<U>$ velocity profiles at $\pi$ phase exhibit a positive overshoot above ripple offshore side and a negative overshoot above ripple onshore side. Near the bottom, the upward directed $\langle W\rangle$ velocities may cause the sediment lifting up to regions far from the rippled bed. Moreover, these velocities approach to zero at the bottom due to the no slip boundary condition.

According to the continuity principle, the onshore directed velocities decreased moving along the ripple lee flank, and increased moving along the ripple stoss flank. Thus, velocities at phase $1 / 2 \pi$ were bigger at $L_{8}$ than at $L_{2}$; analogously, velocities at phase $3 / 2 \pi$ were bigger at $L_{2}$ than at $L_{8}$ (Figure $7 a, b)$.

Above the sloping bed (Figure $8 \mathrm{a}-\mathrm{d}$ ), $\langle U\rangle$ and $\langle W\rangle$ velocity profiles were skewed at both locations $L_{2}$ and $L_{8}$. The highest positive depth averaged $\langle U\rangle$ velocities were early reached, i.e., at $13 / 32 \pi$ phase, at both locations (Figure $8 \mathrm{a}, \mathrm{b}$ ). In addition, the highest negative phase averaged $\langle U\rangle$ velocities were reached, respectively, at $40 / 32 \pi$ and at $38 / 32 \pi$. The vertical velocity component at $L_{2}$ showed the maximum at $13 / 32 \pi$ and the minimum at $34 / 32 \pi$ (Figure $8 \mathrm{c}$ ); only above the onshore ripple flank, the maximum phase averaged velocity was reached exactly at $1 / 2 \pi$, while the minimum occurred at $37 / 32 \pi$ (Figure $8 \mathrm{~d}$ ).

As a consequence of the asymmetry, the positive half period of the ensemble averaged velocity lasts for a shorter time than the negative half period throughout the water depth. Indeed, at $P_{2}$ both $\langle U\rangle$ and $\langle W\rangle$ velocity profiles were considerably negative at $\pi$ phase, (Figure $8 \mathrm{a}-\mathrm{d}$ ). At $L_{2}$ near the bed, $<W>$ is upward directed both during the positive and the negative half cycles (Figure $8 \mathrm{~d}$ ). As expected, the wave asymmetry triggered by the sloping bed, made the onshore directed $\langle U\rangle$ component bigger in modulus at the phase of the maximum depth averaged velocity than the one at the phase of the minimum depth averaged velocity. Higher velocities in the positive half cycle cause stronger turbulent fluctuations than in the negative half cycle.

The turbulent kinetic energy varied from 0 to $0.2 \mathrm{~cm}^{2} / \mathrm{s}^{2}$ above the offshore flank ( $L_{2}$ location) of both ripples (Figures 9a and 10a). Turbulence was negligible at the bottom due to the no-slip condition, and then it increased due to the vorticity generated by the rippled bed. Moving away from the bottom, turbulence decreased. More in detail, at $P_{1}$, turbulence reached values close to zero moving upward 
starting from $z / d=0.1$; at $P_{2}$, the flow was more turbulent due to the wave breaking, which occurred just up ahead in the channel and to the larger fluid velocity. Thus, turbulent kinetic energy profiles exhibit a positive gradient at $z / d=0.55$. Turbulence generated by wave breaking can also explain why in $P_{2}$ there was a greater difference between the tke profiles in different phases than in $P_{1}$. Furthermore, at both positions, tke reached its maximum when the flow was onshore directed, i.e., at $11 / 32 \pi$ and at $7 / 32 \pi$, respectively. The asymmetry of the turbulence intensity is responsible for the generation of offshore steady streaming [26].

The Reynolds stresses measured at both positions $P_{1}$ and $P_{2}$ ( $L_{2}$ location) are reported in Figures $9 \mathrm{c}$ and 10c, respectively. Above the horizontal bed, Reynolds stresses at the bottom varied from -0.5 to $1.4 \mathrm{~cm}^{2} / \mathrm{s}^{2}$. As expected, the phase averaged Reynolds stress was negative when the velocity gradient was positive and vice versa. At distances from the bottom larger than $3 \mathrm{~cm}$ approximately $(z / d>0.1), \overline{u^{\prime} v^{\prime}}$ became negligible at $P_{1}$. Instead, at the sloping bed Reynolds stresses varied from -1 to $0.4 \mathrm{~cm}^{2} / \mathrm{s}^{2}$ and did not approach zero throughout the investigated water depth. Such phenomenon occurred because of the higher velocities caused by the decreasing of the water depth.

Looking at both tke and Reynolds stress profiles, it is easy to see that the sloping bed did not cause an increase of the near bed turbulence. The turbulent kinetic energy together with the Reynolds stress measured at location $L_{8}$ do not show considerable differences with respect to the offshore ripple flank $L_{2}$ at both $P_{1}$ and $P_{2}$ ripples. Along the sloping bed, turbulence extended throughout the water depth, thus producing a considerable flow stirring. Such a phenomenon could explain the ripple offshore migration observed during the moveable bed campaign [16]. Indeed, because of the flow stirring a lot of sediments are raised far from the bottom. Then, because of the undertow, an offshore sediment transport was generated, which was higher than the onshore directed transport at the bottom and caused the measured offshore ripple migration.

Figure 11 shows the mass transport velocity, which is proportional to $H^{2} T /(L \cdot d)$ (see [27]), measured above the ripple trough (location $L_{5}$ ). A good alignment of both the data above the horizontal bed $P_{1}$ and above the sloping bed $P_{2}$ is observed on the straight line of equation:

$$
\frac{H^{2} T}{L d}=0.0187|\bar{U}|+0.0019
$$

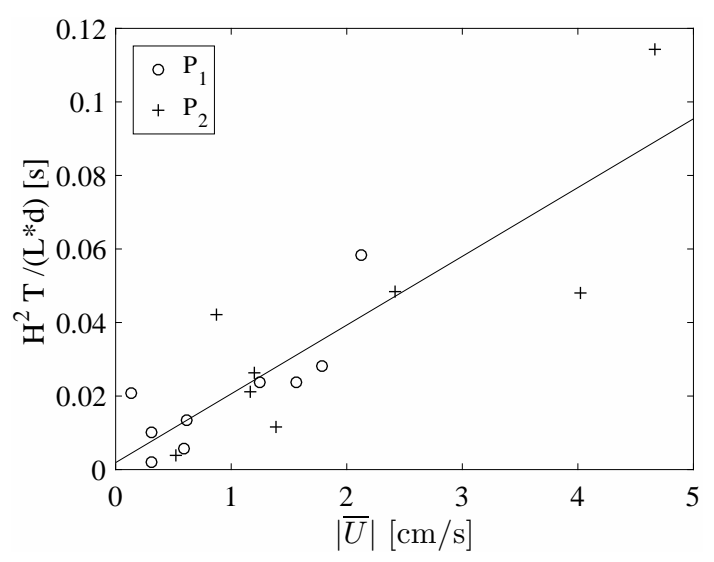

Figure 11. Mass transport velocity at location $L_{5}$.

\subsection{Spatial Analysis}

Figures 12 and 13 show the velocity field between two adjacent ripple crests, measured throughout experiment T9. Both $\langle U\rangle$ and $\langle W\rangle$ velocity components are here considered. Positive, onshore flow is directed to the right. The stoss slope of the ripple is the onshore slope (i.e., the right side of the image) and the lee slope is the offshore slope. Following Van der Werf et al. [28], eight phases per period are plotted in Figures 12a-h and 13a-h: 
- (a) Phase 0: This phase is close to the off-onshore flow reversal, thus the free-stream velocities were close to zero.

- (b) Phase 1/4 $\pi$ : Free stream is accelerating onshore, thus velocities are onshore directed throughout the water column. Ripple shape affected near bed velocities. More in detail, moving from the ripple offshore crest to the ripple trough (locations from $L_{2}$ to $L_{5}$ ) near bed velocities decreased, whereas, moving from the ripple trough to the ripple onshore crest (locations from $L_{6}$ to $L_{9}$ ) near bed velocities increased. At the sloping bed, this phenomenon can be distinguished only above the ripple stoss side.

- (c) Phase $1 / 2 \pi$ : The horizontal component of the free stream velocity is close to its onshore maximum. More specifically, at $P_{2}$ maximum horizontal velocities occurred few instants before phase $1 / 2 \pi$ due to the wave asymmetry. At both positions, the highest velocities were measured at about $1-2 \mathrm{~cm}$ from the bottom where a velocity overshooting occurred. The vertical component of the velocity often showed its maximum from $2 / 32 \pi$ to $3 / 32 \pi$ before $1 / 2 \pi$.

- (d) Phase $3 / 4 \pi$ : Free-stream velocity is decelerating. At $P_{2}$, due to the velocity skewness, velocity profiles were close to the flow reversal.

- (e) Phase $\pi$ : This phase is close to on-offshore flow reversal. At $P_{1}$, the free-stream velocity was weak, except near the bottom where the velocities exhibit a considerable overshooting, which was directed to the ripple trough above both flanks. The return current makes the velocity profiles at $P_{2}$ offshore directed at all the inspected locations.

- (f) Phase $5 / 4 \pi$ : The free stream is accelerating offshore. The offshore directed velocities decreased moving from the ripple $P_{2}$ onshore crest (from $x / \lambda=7 / 8$ at $P_{1}$ ) to the ripple trough and increased moving from the ripple trough to the ripple offshore crest.

- (g) Phase $3 / 2 \pi$ : The free stream velocity is close to its offshore maximum. More specifically, it occurred few instants before for the $U$ component and few instants after for the $W$ component. At $P_{2}$, both components reached the minimum before, at about $38 / 32 \pi$.

- (h) Phase $7 / 4 \pi$ : Offshore free-stream velocity started decelerating.

Before closing this section, we highlight that several studies provided information on the flow field over a rippled bed, as already mentioned in the Introduction. Among them, it is worth mentioning those of Van der Werf et al. [28], Stachurska and Staroszczyk [29] and Marin [30]. However both hydrodynamic and morphological parameters that characterize these experiments are strongly different among each other and also compared to the present investigation. For example, in the work of Van der Werf et al. [28], the Reynolds numbers are more that one order of magnitude higher than present data. Marin [30] used an artificial ripple profile characterized by wavelength smaller than the present one by an order of magnitude. None of the previous studies, however, dealt with sloping bed.Stachurska and Staroszczyk [29] considered a sloping bed but the ripple shape differs from the present one. Moreover, the analyzed data focus on different aspects, more oriented to the sediment motion rather than flow field. Future effort will be devoted to simulate numerically similar flow field using the present results as a benchmark for testing numerical models and deepen the knowledge on near bed hydrodynamics. 

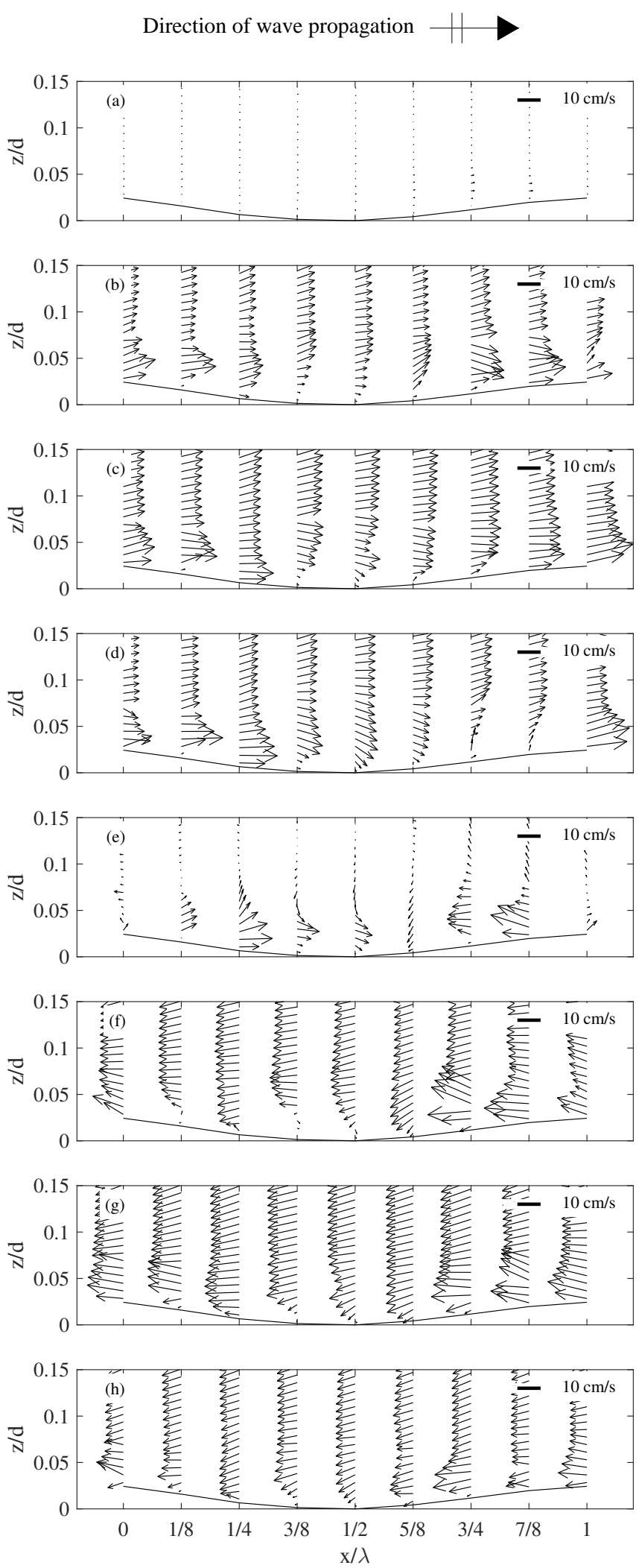

Figure 12. $T 9$ test $(H=5.86 \mathrm{~m}, T=1.26 \mathrm{~s})$, velocity field along ripple $P_{1}$ at eight phases: (a) 0 ; (b) $1 / 4 \pi$; (c) $1 / 2 \pi ;$ (d) $3 / 4 \pi ;$ (e) $\pi$; (f) $5 / 4 \pi ;$ (g) $3 / 2 \pi$; and (h) $7 / 4 \pi$. 

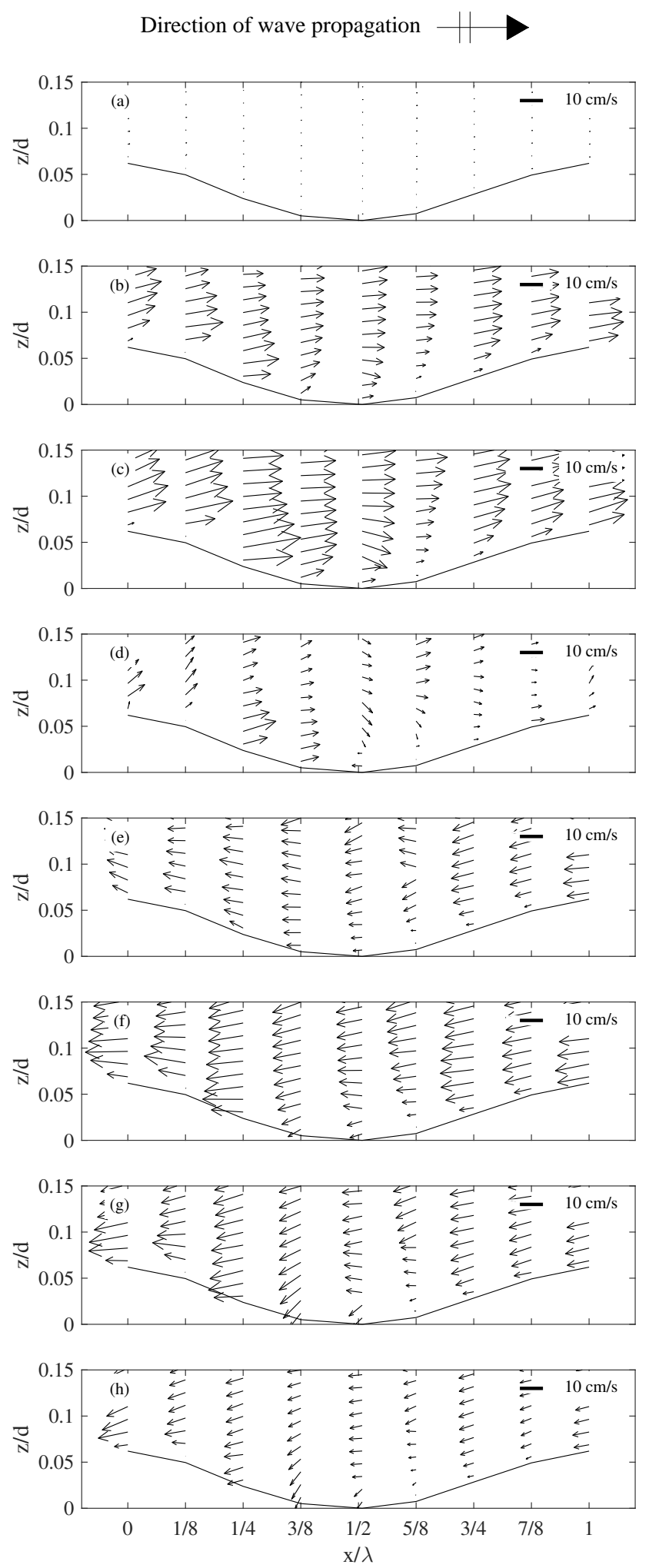

Figure 13. $T 9$ test $(H=5.86 \mathrm{~m}, T=1.26 \mathrm{~s})$, velocity field along ripple $P_{2}$ at eight phases: (a) 0 ; (b) $1 / 4 \pi$; (c) $1 / 2 \pi ;$ (d) $3 / 4 \pi ;$ (e) $\pi ;$ (f) $5 / 4 \pi ;$ (g) $3 / 2 \pi$; and (h) $7 / 4 \pi$.

\section{Conclusions}

An experimental investigation was carried out to analyze the hydrodynamics induced by sea waves propagating over a sloping rippled beach. Two ripples were considered: the first one located above the horizontal bed and the second one located above the sloping bed. Bedforms were 
preliminarily fixed by a thin layer of concrete and inhibited to migrate, thus allowing detailed velocity measurements along two ripples placed at the two locations mentioned above. Waves approaching to the sloping bottom, became strongly asymmetrical, with flat, wide troughs and sharp crests.

Above the horizontal bed, ripples considerably affected the phase averaged velocity profiles. Indeed, velocities measured far from the bottom, where the flow approaches the irrotational condition, were close to zero at both 0 and $\pi$ phases. Instead, near the bottom, ripple lee side triggered the appearance of an onshore directed steady streaming, whereas ripple stoss side gave rise to an offshore directed steady streaming. These two opposite fluxes of opposite sign thus produced symmetric ripples which quickly reached an equilibrium position.

Instead, the sloping bed caused the appearance of a strong return current at all positions along the ripples which made the flow turbulence non-negligible within the investigated water depth, particularly when velocities were onshore directed. Turbulence caused a considerable flow stirring, which, above a non-cohesive bed, could lift the sediment up in the water column. When the sediments reached the region characterized by a strong undertow current, they were transported offshore. This is the mechanism that caused the offshore migration of ripples observed during a previous campaign with a sandy movable bed.

Finally, a mass transport velocity proportional to $H^{2} T$ was observed at both measuring positions. Generally, a higher mass transport occurred above the sloping bed.

Author Contributions: Conceptualization, C.F. and P.S.; methodology, C.F.; software, C.P.; validation, C.F. and P.S.; formal analysis, C.F.; investigation, C.P.; resources, C.F.; data curation, P.S.; writing-original draft preparation, C.F.; writing-review and editing, C.F.; visualization, P.S.; supervision, E.F.; project administration, P.S.; funding acquisition, E.F.

Funding: This research was funded by Italian Ministry of Foreign Affairs and International Cooperation-Earthquake Potential of Active Faults using offshore geological and morphological Indicators (EPAF) Project, and by University of Catania-INterazione Onde-Correnti nella regione coStiera (INOCS) Project.

Acknowledgments: The reviewers are gratefully acknowledged.

Conflicts of Interest: The authors declare no conflict of interest. The funders had no role in the design of the study; in the collection, analyses, or interpretation of data; in the writing of the manuscript, or in the decision to publish the results.

\section{References}

1. Elgar, S.; Guza, R.T.; Freilich, M. Eulerian measurements of horizontal accelerations in shoaling gravity waves. J. Geophys. Res. 1988, 93, 9261-9269. [CrossRef]

2. Ribberink, J.S.; Al-Salem, A.A. Sheet flow and suspension of sand in oscillatory boundary layers. Coast. Eng. 1995, 25, 205-225. [CrossRef]

3. O'Donoghue, T.; Wright, S. Concentrations in oscillatory sheet flow for well sorted and graded sands. Coast. Eng. 2004, 50, 117-138. [CrossRef]

4. Van der A, D.; O’Donoghue, T.; Davies, A.G.; Ribberink, J.S. Experimental study of the turbulent boundary layer in acceleration-skewed oscillatory flow. J. Fluid Mech. 2011, 684, 251. [CrossRef]

5. Scandura, P.; Foti, E.; Faraci, C. Mass transport under standing waves over a sloping beach. J. Fluid Mech. 2012, 701, 460-472. [CrossRef]

6. Scandura, P.; Faraci, C.; Foti, E. A numerical investigation of acceleration-skewed oscillatory flows. J. Fluid Mech. 2016, 808, 576-613. [CrossRef]

7. Van Der A, D.A.; Scandura, P.; O'Donoghue, T. Turbulence statistics in smooth wall oscillatory boundary layer flow. J. Fluid Mech. 2018, 849, 192-230. [CrossRef]

8. Faraci, C.; Foti, E.; Marini, A.; Scandura, P. Waves Plus Currents Crossing at a Right Angle: Sandpit Case. J. Waterw. Port Coast. Ocean Eng. 2015, 138, 339-361. [CrossRef]

9. Sleath, J.F. Sea Bed Mechanics; John Wiley and Sons Inc.: New York, NY, USA, 1984.

10. Blondeaux, P. Sand ripples under sea waves. part I: ripple formation. J. Fluid Mech. 1990, 218, 1-17. [CrossRef] 
11. Nielsen, P. Dynamics and geometry of wave-generated ripples. J. Geophys. Res. Oceans 1981, 86, 6467-6472. [CrossRef]

12. Van Rijn, L.C. Principles of Sediment Transport in Rivers, Estuaries and Coastal Seas; Aqua Publications: Amsterdam, The Netherlands, 1993; Volume 1006.

13. Sekiguchi, T.; Sunamura, T. Effects of bed perturbation and velocity asymmetry on ripple initiation: wave-flume experiments. Coast. Eng. 2004, 50, 231-239. [CrossRef]

14. Testik, F.Y.; Voropayev, S.I.; Balasubramanian, S.; Fernando, H.J.S. Self-similarity of asymmetric sand-ripple profiles formed under nonlinear shoaling waves. Phys. Fluids 2006, 18, 108101. [CrossRef]

15. Blondeaux, P.; Foti, E.; Vittori, G. A theoretical model of asymmetric wave ripples. Philos. Trans. R. Soc. Lond. A Math. Phys. Eng. Sci. 2015, 373, 20140112. [CrossRef] [PubMed]

16. Petrotta, C.; Faraci, C.; Scandura, P.; Foti, E. Experimental investigation on sea ripple evolution over sloping beaches. Ocean Dyn. 2018, 68, 1221-1237. [CrossRef]

17. Liu, Y.; Faraci, C. Analysis of orthogonal wave reflection by a caisson with open front chamber filled with sloping rubble mound. Coast. Eng. 2014, 91, 151-163. [CrossRef]

18. Faraci, C.; Foti, E.; Scandura, P. Reflection of Sea Waves by Combined Caissons. J. Waterw. Port Coast. Ocean Eng. 2015, 141, 04014036. [CrossRef]

19. Faraci, C. Experimental investigation of the hydro-morphodynamic performances of a geocontainer submerged reef. J. Waterw. Port Coast. Ocean Eng. 2018, 144, 04017045. [CrossRef]

20. Mansard, E.P.; Funke, E. The measurement of incident and reflected spectra using a least squares method. Coast. Eng. 1980, 154-172. [CrossRef]

21. Thomas, R.; Schindfessel, L.; McLelland, S.; Creëlle, S.; De Mulder, T. Bias in mean velocities and noise in variances and covariances measured using a multistatic acoustic profiler: The nortek vectrino profiler. Meas. Sci. Technol. 2017, 28, 075302. [CrossRef]

22. Van Der A, D.A.; Van Der Zanden, J.; O’Donoghue, T.; Hurther, D.; Cáceres, I.; McLelland, S.J.; Ribberink, J.S. Large-scale laboratory study of breaking wave hydrodynamics over a fixed bar. J. Geophys. Res. Oceans 2017, 122, 3287-3310. [CrossRef]

23. Yoon, H.-D.; Cox, D.T. Large-scale laboratory observations of wave breaking turbulence over an evolving beach. J. Geophys. Res. Oceans 2010, 115. [CrossRef]

24. Goring, D.G.; Nikora, V.I. Despiking acoustic doppler velocimeter data. J. Hydraul. Eng. 2002, 128, 117-126. [CrossRef]

25. Longuet-Higgins, M.S. Mass transport in water waves. Philos. Trans. R. Soc. Lond. A Math. Phys. Eng. Sci. 1953, 245, 535-581. [CrossRef]

26. Scandura, P. Steady streaming in a turbulent oscillating boundary layer. J. Fluid Mech. 2007, 571, $265-280$. [CrossRef]

27. Dean, R.G.; Dalrymple, R.A. Water Wave Mechanics for Engineers and Scientists; World Scientific Publishing Company: Singapore, 1991; Volume 2.

28. Van der Werf, J.; Doucette, J.; O’Donoghue, T.; Ribberink, J. Detailed measurements of velocities and suspended sand concentrations over full-scale ripples in regular oscillatory flow. J. Geophys. Res. Earth Surf. 2007, 112. [CrossRef]

29. Stachurska, B.; Staroszczyk, R. Laboratory study of suspended sediment dynamics over a mildly sloping sandy seabed. Oceanologia 2019, 61,350-367. [CrossRef]

30. Marin, F. Eddy viscosity and Eulerian drift over rippled beds in waves. Coast. Eng. 2004, 50, 139-159. [CrossRef]

(C) 2019 by the authors. Licensee MDPI, Basel, Switzerland. This article is an open access article distributed under the terms and conditions of the Creative Commons Attribution (CC BY) license (http:// creativecommons.org/licenses/by/4.0/). 